\title{
ОСОБЕННОСТИ МЕХАНИЗМА ПРИЗНАНИЯ ПРОФЕССИОНАЛЬНОЙ КВАЛИФИКАЦИИ РОССИЙСКИХ СПЕЦИАЛИСТОВ ПО СТРАХОВОЙ ДЕЯТЕЛЬНОСТИ ЗА РУБЕЖОМ
}

\section{FEATURES OF THE MECHANISM OF RECOGNITION OF PROFESSIONAL QUALIFICATIONS OF RUSSIAN SPECIALISTS IN INSURANCE ACTIVITIES ABROAD}

\section{O. Bashlakova}

Summary. This article discusses issues related to the functioning of the system of international recognition of professional qualifications in the field of insurance of Russian specialists as an important link in the integration of the Russian insurance market with leading foreign insurance markets. Based on the analysis of existing mechanisms for the recognition of professional qualifications in insurance abroad, proposals are made for the Russian insurance market in order to standardize these processes.

Keywords: professional qualification, insurance specialist, diploma nostrification, Lisbon Convention, professional associations.
$\mathbf{H}$ а современном этапе развития страхового рынка Российской Федерации успех его дальнейшей интеграции с ведущими страховыми рынками за рубежом будет в значительной степени зависеть от возможности взаимного признания профессиональных квалификаций специалистов, работающих в данной сфере деятельности.

Под профессиональной квалификацией понимают определенную ступень профессиональной подготовленности работника к выполнению того или иного вида труда определенного качества и сложности. Это система конкретных знаний, навыков, умений, обеспечивающих выполнение профессиональной деятельности и отражающих годность специалиста к какому-либо виду труда [1].

В настоящее время для Российской Федерации главной международно-правовой основой для признания профессиональных квалификаций является Лиссабонская Конвенция. В соответствии с Федеральным законом от 04.05.2000 г. № 65-Ф3 «О ратификации Конвенции о признании квалификаций, относящихся к высшему образованию в европейском регионе» принципы данной Конвенции распространяются на Российскую Федерацию.
Башлакова Ольга Игоревна

Ассистент, Финансовый университет при Правительстве Российской Федерации OlBashlakova@fa.ru

Аннотация. В данной статье рассматриваются вопросы, связанные с функционированием системы международного признания профессиональных квалификаций в области страхования российских специалистов как важного звена процессов интеграции российского страхового рынка с ведущими зарубежными страховыми рынками. На основании анализа существующих механизмов признания профессиональных квалификаций по страхованию за рубежом, даны предложения для российского страхового рынка с целью стандартизации данных процессов.

Ключевые слова: профессиональная квалификация, специалист по страхованию, нострификация диплома, Лиссабонская Конвенция, профессиональные ассоциации.

Лиссабонская Конвенция была разработана такими международными организациями, как Совет Европы и ЮНЕСКО, и принята в Лиссабоне 11 апреля 1997 года. Основная цель создания Конвенции состоит в том, чтобы гарантировать подписавшей ее сторонам возможность признания их профессиональных квалификаций на территории других стран.

Основные принципы Лиссабонской Конвенции состоят в следующем [2]:

1. Обладатели квалификаций, выданных в одной стране, должны иметь надлежащий доступ к оценке этих квалификаций в другой стране.

2. Каждая страна должна признать квалификации, выданные другими странами и отвечающие общим требованиям для доступа к высшему образованию.

3. Признание квалификации высшего образования, выданной в другой стране, должно влечь за собой одно или больше из следующих последствий:

- доступ к дальнейшему обучению в системе высшего образования, включая соответствующие экзамены и/или подготовку по программам, ведущим к получению ученой степени, на условиях 
Таблица 1. Организации, курирующие признание российских квалификаций и основные параметры оценки для принятия решения [3].

\begin{tabular}{|c|c|c|c|c|}
\hline Страна & $\begin{array}{l}\text { Организация } \\
\text { ответственная } \\
\text { за признание } \\
\text { квалификации } \\
\text { в сфере } \\
\text { образования }\end{array}$ & $\begin{array}{l}\text { Параметры } \\
\text { для оценки } \\
\text { при признании } \\
\text { квалификации } \\
\text { в сфере образования }\end{array}$ & $\begin{array}{l}\text { Организация } \\
\text { ответственная } \\
\text { за признание } \\
\text { профессиональной } \\
\text { квалификации }\end{array}$ & $\begin{array}{l}\text { Параметры для оценки при } \\
\text { признании профессиональной } \\
\text { квалификации для } \\
\text { регламентируемых профессий }\end{array}$ \\
\hline Германия & $\begin{array}{l}\text { высшие учебные } \\
\text { заведения страны }\end{array}$ & $\begin{array}{l}\text {-нормативный } \\
\text { и фактический период } \\
\text { обучения } \\
\text { содержание } \\
\text { образовательной } \\
\text { программы } \\
\text { Результаты } \\
\text { обучения }\end{array}$ & $\begin{array}{l}\text { Центральный офис } \\
\text { по иностранному } \\
\text { образованию }\end{array}$ & $\begin{array}{l}\text { - диплом о высшем образовании } \\
\text { по професии в ВУЗе, прошедшем } \\
\text { сертификацию. }\end{array}$ \\
\hline Испания & $\begin{array}{l}\text {-Министерство } \\
\text { образования, культуры } \\
\text { и } \\
\text { спорта } \\
\text { высшие учебные } \\
\text { заведения }\end{array}$ & $\begin{array}{l}\text {-нормативный } \\
\text { и фактический срок } \\
\text { обучения } \\
\text { объем изученной } \\
\text { программы }\end{array}$ & $\begin{array}{l}\text {-Министерство } \\
\text { образования, культуры } \\
\text { и спорта }\end{array}$ & $\begin{array}{l}\text { - диплом } \\
\text { наличие профессионального стажа } \\
\text { информация о правах предоставляемых } \\
\text { обладателю квалификации в стране ее } \\
\text { получения }\end{array}$ \\
\hline Франция & $\begin{array}{l}\text { Международный } \\
\text { центр по образованию }\end{array}$ & $\begin{array}{l}\text { - период обучения } \\
\text { объем полученных } \\
\text { знаний }\end{array}$ & $\begin{array}{l}\text { Международный } \\
\text { центр по образованию }\end{array}$ & $\begin{array}{l}\text {-диплом } \\
\text { наличие профессионального стажа } \\
\text { наличие сертификата или лицензии } \\
\text { для осуществления профессиональной } \\
\text { деятельности у себя в стране. }\end{array}$ \\
\hline
\end{tabular}

аналогичных тем, которые применяются к обладателям квалификаций кандидатов страны, в которой запрашивается признание;

- использование ученой степени в соответствии с законами и постановлениями страны, в которой запрашивается признание;

- признание может облегчить доступ на рынок труда

Однако, необходимо отметить, что участие Российской Федерации в Лиссабонской Конвенции не означает, что признание профессиональных квалификаций, полученных на ее территории, будет осуществляться всеми странами - участницами автоматически.

Согласно статье 1 настоящей Конвенции под признанием квалификаций понимается «официальное подтверждение полномочным органом значимости иностранной образовательной квалификации в целях доступа ее обладателя к образовательной и/или профессиональной деятельности» [2]. Исходя из этой формулировки каждая страна - участница Конвенции назначает свой компетентный орган, который отвечает за признание квалификации в сфере академического образования и профессиональной деятельности.

Рассмотрим более подробно каким образом в настоящее время осуществляется признание российских про- фессиональных квалификаций в области страхования за рубежом.

В настоящее время все профессии на территории стран ЕС подразделяются на нерегулируемые и регулируемые.

Нерегулируемые профессии характеризуются прежде всего отсутствием требования к наличию определенной квалификации и необходимости соблюдения дополнительных правил. Если иностранный соискатель изъявляет желание работать в ЕС в рамках нерегулируемой профессии, квалификация по которой подтверждена соответствующим дипломом, выданным в его стране, в этом случае ему не понадобиться его легализация.

Профессии, в рамках которых специалист принимает решения в жизненно важных для страны отраслях экономики, таких, как медицина, образование, строительство, финансовый рынок относятся на территории стран ЕС к категории регулируемых. Такие профессии регулируются на государственном уровне посредством специальных законов. Для регулируемых профессий установлены специальные профессиональные квалификации, уровень образования, определенные требования к допуску до профессиональной деятельности посредством сдачи специального государственного экзамена на сертификацию, прохождение стажировки. 
Профессия специалист по срахованию на территории стран ЕС относится к категории регулируемых. Это означает, что соискатель из России на вакансию по данной профессии в обязательном порядке должен подтвердить свою квалификацию.

Основные этапы процедуры признания профессиональной квалификации для регилируемой профессии специалист страхового рынка на территории стран ЕС заключаются в следующем:

1. Определение степени образования. На первом этапе происходит процедура нострификации дипломов о высшем образовании, полученных специалистами в области страхования в России. В каждой из стран ЕС есть свой уполномоченный орган, который отвечает за данную процедуру. Как правило, это Министерство по образованию, национальные советы или международные центры по образованию, а также высшие учебные заведения. В процессе нострификации дипломов проводится анализ сроков обучения, оценка уровня, содержания и объема образовательной программы, по которой происходило обучение специалистов в области страхования в ВУЗах Российской Федерации.

2. Оценка стажа работы по профессиональной квалификации. На втором этапе органы, уполномоченные проводить процедуру признания профессиональных квалификаций, к их числу относят Министерство по образованию и культуре, профессиональные ассоциации, работодателей, изучают опыт работы соскателя с целью подтверждения его профессиональной квалификации в качестве специалиста по страхованию. Как правило, для подтверждения своей профессиональной квалификации соискателю необходим стаж работы в области страхования не менее 3 лет. При оценке стажа работы в рамках подтверждаемой профессиональной квалификации в расчет может быть принят опыт работы в сопряженной сфере деятельности в рамках одной отрасли. При проведении анализа стажа работы положительно оцениваются длительные командировки и стажировки за рубеж сосискателя для подтверждения его профессиональной квалификации в области страхования.

3. Сдача государственного экзамена. Важным этапом для подтверждения профессиональной квалификации специалиста в области страхования является сдача государственного экзамена, который состоит из двух частей. Первая часть экзамена связана с оценкой уровня знаний иностранного языка. Особое внимание при сдаче экзамена уделяется тому, насколько хорошо соискатель владееет профессиональной лексикой в области страхования. В ходе второй части экзамена, которая является основной, оцениваются теоретические и практические знания сосискателя по профессии специалист в области страхования.

Государственный экзамен на подтверждение профессиональной квалификации в области страхования могут принимать только специально аккредитованные центры. На сегодняшний день самое большое количество центров оценки профессиональной квалификации, а именно 150, представлено в Великобритании. В остальных странах ЕС количество центров не превышает 50 единиц [4].

В случае успешной сдачи всех экзаменов соискателю выдается специальный сертификат, который и является подтверждением признания его профессиональной квалификации в области страхования.

4. Вступление в профессиональную ассоциацию. Завершающим этапом подтверждения профессиональной квалификации в области страхования уже сертефицированного соискателя является его вступление в соответствующую профессиональную ассоциацию. Роль таких профессиональных ассоциации заключается в стимулировании развития отрасли экономики через процесс консультаций, обмена опытом, наработками между специалистами в области страхования. США, Канада и Австралия также присоединились к Лиссабонской Конвенции, в результате процесс признания профессиональной квалификации специалистов по страхованию из России во многом похож на процесс описанный выше для стран ЕС.

Определенные отличия в системе признания профессиональной квалификации специалистов по страхованию есть в США.

Оценкой профессиональной квалификации специалистов по страхованию занимаются организации, которые входят в состав ассоциации независимых неправительственных компаний - National Association of Credential Evaluation Services (NACES) [3].

Первый этап признания профессиональной квалификации специалиста по страхованию в США заключается в нострификации диплома. Полученный в Российской Федерации диплом по специальности специалист по страхованию оценивается по следующим критериям[3]:

- изученные дисциплины (количество, характеристика);

- количество академических часов за время всего образовательного процесса (переводятся в американские баллы); 
- все пройденные за время обучения стажировки и практики;

- экзамены и зачеты (описание дисциплин, оценки, которые переводятся в американские грейды)

В процессе нострификации российского диплома в соответствии с американскими образовательными стандартами квалификация может понизиться. Так, например, российский диплом с уровнем магистра может быть преобразован в американский аналог, но уже с уровнем бакалавра. В этом случае соискателю будет предложено продолжить свое обучение в американских ВУЗах для получения диплома магистра.

На втором этапе подтверждения профессиональной квалификации специалиста по страхованию соискателю требуется пройти специальный экзамен, состоящий из тестовых заданий и нескольких практических задач.

В случае успешного прохождения соискателем всех двух вышеописанных этапов подтверждения квалификации ему выдается сертификат об образовании, соответствующий американским стандартам. В сертификате в обязательном порядке указывается организация, которая его выдала.

Если говорить про признание российских профессиональных квалификаций странами Латинской Америки, Африки и Азии, то в настоящий момент этот процесс регламентируется отдельными соглашениями между конкретными странами, входящими в данные регионы. Главным недостатком таких соглашений является отсутствие в них четкого описания процедуры и критериев оценки при осуществлении признания профессиональной квалификации полученной в одной из стран соглашения другой страной.

В настоящее время признание российских профессиональных квалификаций страхового рынка за рубежом не носит массовый характер и связано это с тем, что на сегоднешний день нет специального документа международного уровня, в котором был бы четко регламентирован данный процесс.

Изучив существующий опыт признания профессиональных квалификаций за рубежом, можно сформулировать следующие предложения по международному признанию российских профессиональных квалификаций страхового рынка:

1. На сегоднешний день Лиссабонская Конвенция (1997 г.) является единственным документом международного уровня, который регламентирует процесс признания иностранных профессиональных квалификаций. Именно на базе этого международного документа Российская Феде- рация выстраивает процесс взаимного признания профессиональных квалификаций на своей территории и на территории стран - участниц Конвенции.Таким образом можно говорить о целесообразности оформления всех предложений по международному признанию росиийских профессиональных квалификаций страхового рынка в рамках специальных дополнений и/или соглашений к Лиссабонской Конвенции.

2. Основным этапом в процессе признания российской профессиональной квалификации страхового рынка является признание диплома о высшем образовании, который выдается специалистам в области страхования. В этой связи необходимо, чтобы процесс нострификации диплома был максимально ясен и прозрачен, как для российской стороны, так и для стран участниц процесса признания. С этой целью необходимо:

- выделить в странах - участницах Конвенции ВУЗы - флагманы, которые готовят специалистов для страхового рынка, предварительно согласовав этот список с зарубежными партнерами;

- изучить основные стандарты образовательного процесса при подготовке специалистов для страхового рынка в выделенных ВУЗах (основные дисциплины, количество академических часов, перечень экзаменов, стажировки и практические занятия, требования к итоговой аттестации);

- сформировать и согласовать унифицированную версию требований и стандартов необходимых для автоматического признания российского диплома специалиста по страхованию во всех странах - участницах Лиссабонской Конвенции;

- сравнить унифицированные требования и стандарты к автоматическому признанию российских дипломов специалистов по страхованию с существующими образовательными программами российских ВУЗов - флагманов, которые готовят специалистов по страховому делу;

- сформулировать основные отличия российской образовательной системы при подготовке специалистов по страхованию от унифицированных стандартов и критериев согласованных для автоматического признания дипломов странами - участницами Конвенции;

- внести необходимые изменения в российские образовательные программы при подготовке специалистов по страховому делу.

3. Важным этапом процесса признания российских профессиональных квалификаций страхового рынка является сертификация специалиста, которая может осуществляться в том случае, если у соискателя на должность специалиста по страхованию нет практического опыта работы в соответствующей отрасли, но есть подтвержденный 
диплом, либо обратная ситуация, есть практический опыт работы в страховом бизнесе в России, но нет профильного образования. В этом случае для подтверждения своей профессиональной квалификации соискателю необходимо пройти специальный экзамен.Принимать такие экзамены могут только специально аккредитованные центры. В настоящее время в Российской Федерации существует 9 независимых центров, которым делегировано право по оценке профессиональной квалификации в финансовой сфере. Для того, чтобы результаты оценки профессиональной квалификации российских независимых центров признавались на международном уровне необходимо, чтобы эти центры прошли процедуру аккредитации.В этом случае сертификаты, подтверждающие профессиональную квалификацию российских специалистов в области страхования будут признаваться за рубежом.
4. В настоящее время процесс оценки профессиональной квалификации в России не носит обязательный характер и является платной процедурой. Для того, чтобы процедура международного признания российской профессиональной квалификации страхового рынка носила повсеместный характер необходимо сделать существующую в России систему оценки обязательной и бесплатной.

5. Необходимо выделить независимые центры оценки профессиональной квалификации, которые будут заниматься подтверждением профессиональной квалификации исключительно специалистов в области страхования.Такая специализация поможет более детально прорабатывать критерии и стандарты оценки специалистов на международном уровне и будет способствовать процессу аккредитации специализированных оценочных центров.

\section{ЛИТЕРАТУРА}

1. Энциклопедический словарь педагога//Безрукова В.С.: Екатеринбург 2000 г — С. 109

2. Конвенция о признании квалификаций, относящихся к высшему образованию в Европейской регионе от 11.04 .1997 (Лиссабон).

3. ФГБУ «Главэкспертцентр»/Документы/Признание российских квалификаций за рубежом.Режим доступа nic.gov.ru(01.03.2020)

4. Разработка профессиональных стандартов. Опыт зарубежных стран.//Агентство стратегических инициатив-Режим доступа www.labrate.ru (01.03.2020)

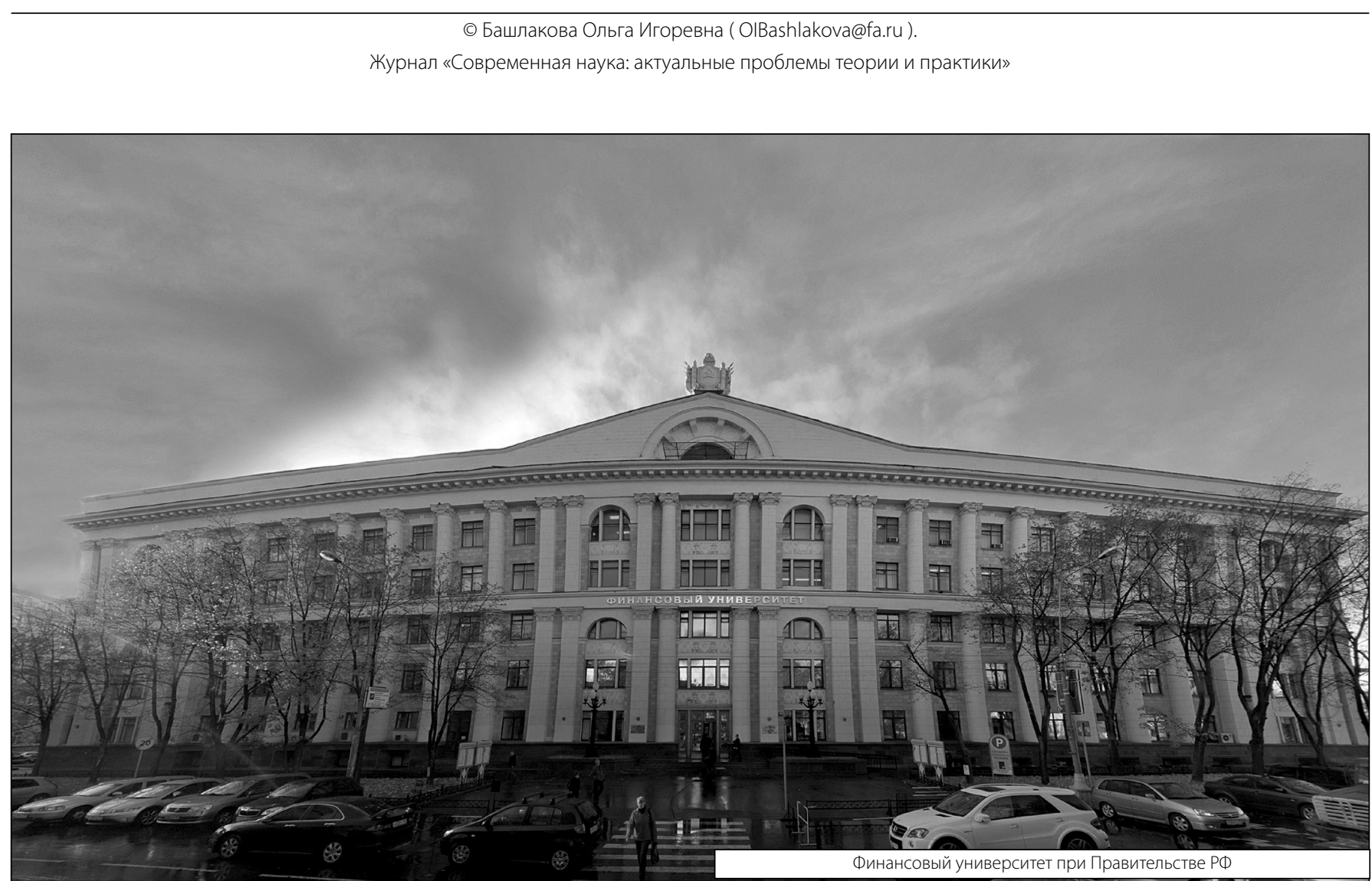

